\title{
Research on the Sustainable Development and Implementation Strategy of Study Tours Industry
}

\author{
Chao Liu", Jinwei Yang \\ College of Art and Design, Wuhan Textile University, Wuhan, Hubei, China \\ *Corresponding Author.
}

\begin{abstract}
As an emerging education mode, study tours started late in China, but it has developed rapidly in a short time. Generally speaking, study tours industry has a great space for development in the future, but there are still many problems in its development process. By analyzing its development status, this paper studies its existing problems, analyzes its sustainable development from the perspective of social demand, puts forward the implementation strategy of sustainable development, and explains it in combination with practice, which has reference significance for the future development of study tours.
\end{abstract}

Keywords: study tours industry, development status, sustainability research, implementation strategies

\section{Introduction}

In recent years, study tours have been carried out all over the country. At present, study tours have been carried out all over the country. At present, scholars and research institutions in this field of research show less cooperation and scattered research characteristics; the research content shows gradually deepening and diversified research topics; study tours hotspots mainly include value connotation, curriculum standards, core literacy, practical education, quantitative demands of research students, parents, teachers, enterprises and important factors affecting their participationI.[1]. Less often. This paper analyzes the current development situation of study tours, analyzes the sustainable development of study tours in China with social needs as the starting point, puts forward the sustainable development implementation strategy, and explains it combined with practice, to provide new ideas for the future study tours development.

\section{Development Status}

2.1 Study tours in China develops a short time and fast

Although the study tours has a long history, it has begun to develop briefly in the modern Chinese sense, but the development speed is very amazing.

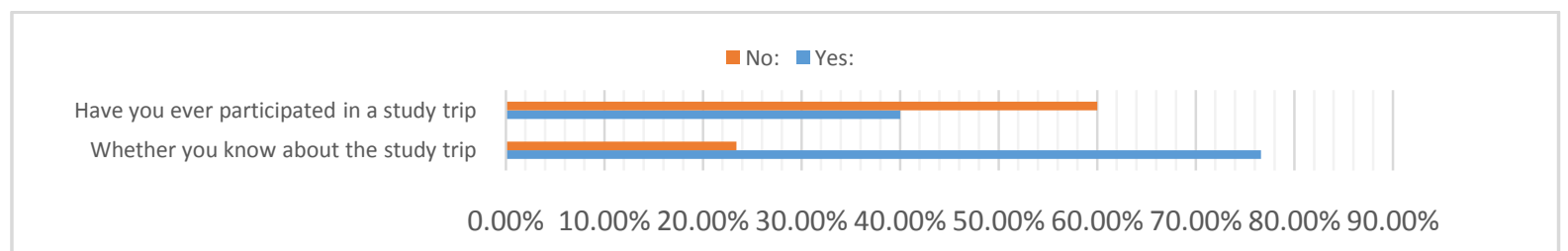

Fig 1: Whether you have participated in the study trip, and whether you know the study tours (source: "China study tours Development News 2017”)

According to the China study tours Development Report released by the China Tourism Institute in $2017,40 \%$ of respondents participated and $60 \%$ did not participate in study tours; $77 \%$ understood the study tours, and $23 \%$ did not know study tours (Figure 1).

ISSN: 0010-8189

(C) CONVERTER 2021 


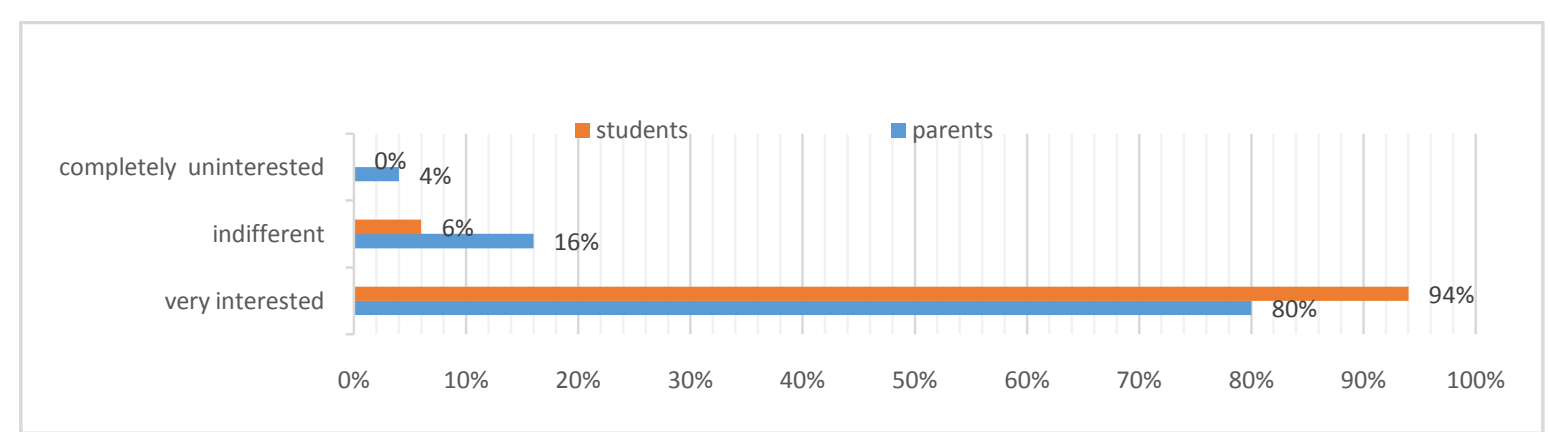

Fig 2: Attitude towards study tours (Source: China study tours Development News 2017) (source: "China study tours Development News 2017”)

Judging from the attitude of parents and students towards study tours, $94 \%$ of students and $80 \%$ of parents are very interested in study tours activities, accounting for the vast majority of the respondents. (Fig. 2)

The above data show that in China, the study tours education model has been recognized and accepted by most people, but some people are not familiar with this education model. Therefore, study tours still has a lot of space for development.

2.2 Study tours destination and base construction was vigorously launched

In 2018, the Ministry of Education announced that 377 units such as the South China Army Fleet of the PLA Navy were the "National Research and Education Base for Research and Practice for Primary and Secondary School Students", and 26 units such as Beijing Automation Engineering School were the "National Research and Practice Education Camp for Primary and Secondary School Students"[2]. In science and culture has greatly enriched the study tours resources. Study tours destinations and bases have rich types and numerous bases, which have laid a good foundation for the development of study tours.

2.3 Is in the infancy of high-quality development

According to the 2020 people's daily text brigade think tank released "China study tours development white paper 2019" data, according to incomplete statistics, more than 7300 enterprises mainly involved in study tours business in 2019, by the end of August 2020, the national primary and secondary school students study practice education base more than 1600,177 national primary and middle school students study practice education camp. The market scale expanded rapidly, the scale of investment and financing increased, and the study tours products began to show diversified and personalized characteristics. At present, study tours is in the initial stage of high-quality development, and there are still some problems to be solved urgently.

\section{Problems Existing in the Current Study Tours}

3.1 The level of regional development is unbalanced. The development level of study tours in economically developed areas is higher than that in economically backward areas, and the development level of study tours in areas with rich tourism resources is higher than that in areas with poor tourism resources.

3.2 There is a lack of study tours in rural areas. In China, study Tours are mainly carried out in schools in urban areas. However, due to backward economic conditions in rural areas and insufficient funds for study, research activities cannot be effectively implemented I.[3]. Secondly, teachers in rural areas are weak, lack of research experience, professional degree is not high. In addition, the popularization and publicity of study trips in rural areas are relatively low, and the acceptance of students' parents is relatively low.

3.3 Study tours teachers need to be improved. The allocation of tutors in activities is usually divided into school

ISSN: 0010-8189 
teachers, leading teachers and professional instructors (usually refer to professional teachers in professional research institutions or university, or professional workers in a certain field or a certain institution).

Teachers (or tour guides) of research institutions are good at organizing and management in research activities and have more experience in the resources of "traveling", but they lack of professionalism in "learning". Secondly, some tourism institutions have a low number and quality of research tour guides, and it is difficult for the knowledge structure and skills to ensure the quality of tour guides I.[4]. Teachers are usually teachers from relevant disciplines. Teachers are good in subject knowledge, but lack experience in planning and management of study tours, focusing on "learning". Professional instructors have authoritative authority in the professional field, and they should pay attention to the grasp of the course difficulty in the activities.

In short, high-quality research activities need effective communication and cooperation between the above three. The organization and management of the activities, the teaching plan and the implementation of the activities are unified in the specific research activities, which is a test to the comprehensive ability of the research tutor.

3.4 Poor evaluation standard.The complete study trip should be evaluated and reflected after the activity, but in the actual activity process, the evaluation link is often ignored. Due to the diversified and personalized characteristics of course activities, evaluation activities have certain complexity, and have certain difficulties in establishing evaluation standards, and it is difficult to get the effect or quality of research activities with timely feedback.

3.5 Activity content planning needs to be improved. The theme of study tours activities has a direct impact on the play of educational value in the process of study activities. At present, many schools still lack the thinking about the theme, goal and educational significance of travel in the course design of study travel, which makes the study tours fall into a vicious circle of "paying more attention to travel and neglecting learning" and "taking a quick look at the scenery". At present, the design of study tours routes for primary and secondary schools in various regions of China is mainly based on tourist routes, and most of them are scenic spots for visiting. Some areas planned for tourist routes have little significance for students' learning I.[5].

\section{Sustainable Development of Study Tours}

\subsection{National Planning for Quality Education Development}

Due to the unique "learning" and "tour" teaching mode of study travel, which plays an important role in cultivating students' practical ability and comprehensive quality, this practical education mode fits the concept of education innovation, and is the key task of the education and teaching reform in China, meeting the needs of contemporary quality education development.

The policies launched by the State Council, the Ministry of Education, the Tourism Administration and other departments, as well as the provinces and local governments in a more important position, shows that the future development of study travel has been strongly supported at the policy level. For example, in November, 2016, the opinions on promoting primary and secondary school students study tourism, fully affirmed the significance of study travel, study travel formally into the primary and secondary school education teaching plan, into the school comprehensive evaluation and credit management system, not only conducive to mobilize the enthusiasm of schools to participate in, also help to solve the safety of the study travel market, study travel market demand has been released in a large number. The introduction of various policies has promoted the development of quality-oriented education, which can reasonably infer that the future policy dividends will continue to be released, and there is great potential for the development of study travel.

4.2 Social needs for economic development

ISSN: 0010-8189

(C) CONVERTER 2021 


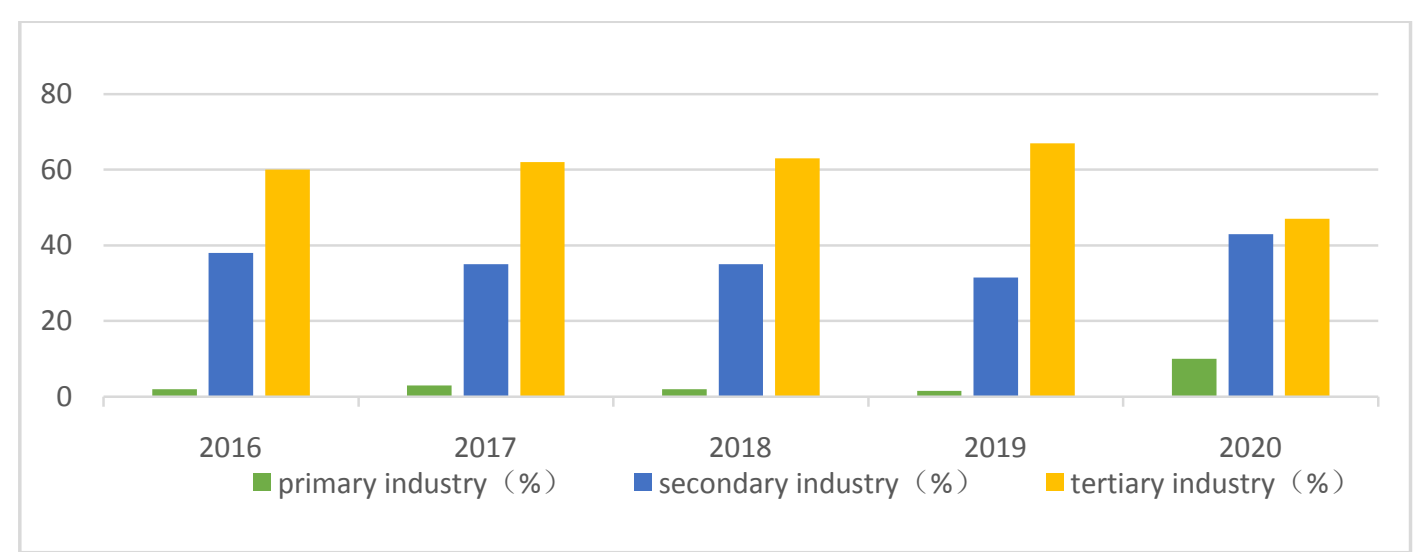

Fig 3: The Contribution of Chinese Industries to GDP in the past five years (Source: National Bureau of Statistics)

In the past five years, the contribution rate of the tertiary industry to China is more than 55\% of the total GDP value (Fig3), ranking first among the tertiary industries. As a kind of tourism, study travel is an important growth point for the future development of tourism, which is closely related to the overall development of the national economy and drives the development of the tertiary industry. The development of study travel can effectively increase regional income and create more employment opportunities, which is also a good way to balance the regional economic structure. In mountainous areas or villages with rich natural resources but underdeveloped economic development, study travel can be deeply integrated with local resources, and become a new highlight of the economic development of the region.

4.3 Meet the family needs of child quality education

With the improvement of China's economic level, household income and consumption level are also significantly improved, and the importance of quality education is constantly improved.

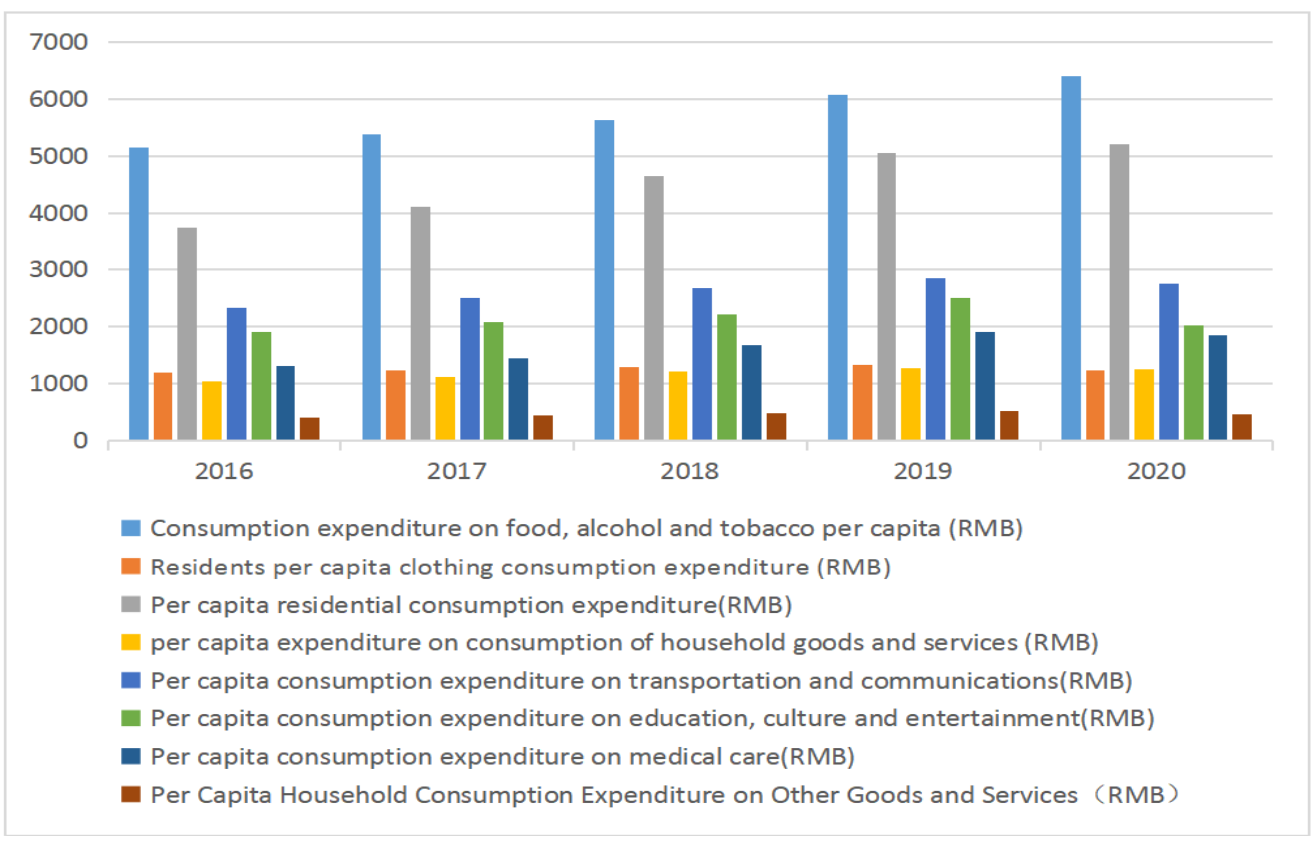

Fig 4: Per Capita Household Consumption Expenditure (Source: National Bureau of Statistics)

ISSN: 0010-8189 
China's top four per capita consumption expenditure are food, housing, transportation and communication, education, culture and entertainment (Fig 4).In the 2017 China Family Quality Education Consumption Report, some parents born after $70 \mathrm{~s}$ and $80 \mathrm{~s}$ living in first-tier and second-tier cities were investigated, and a total of 6,301 effective questionnaires were collected ${ }^{\mathrm{I}\left[{ }^{[6]}\right.}$. According to the survey results, $80 \%$ of parents tend to participate in their children in study trips and camp projects to improve their children's comprehensive ability. Families spending more than 10,000 yuan in quality education account for $60 \%$, and parents pay more and more attention to the teaching content, teaching quality and service, and attach full attention to their children's interest.

With the upgrading of education consumption of Chinese families, parents not only care about their children's academic achievements, but also pay more attention to the cultivation of their children's comprehensive ability, and have a great demand for the new quality-oriented education mode of learning and study travel.

\section{Implementation Strategy for Sustainable Development}

According to the above needs of the three parties and the current problems of study travel mentioned above, this study believes that the implementation strategy can be put forward from the following 5 aspects, and combined with the development practice of research tourism project in Xingshan County, Yichang City, to promote the sustainable development of research tourism.

\section{1 establishes a perfect research product system}

Tour, not a simple walk, but a combination of the subject teaching content and local regional characteristics, so as to truly let the students "have what they learn in the tour, thinking in the line". In the design of research activities, the designer must be clear the purpose and requirements, combined with the geographical advantages, tourism resources, cultural characteristics and the development of different routes, rooted in local development, reasonable arrangement for different courses, students study travel theme of different ages of design weekly study travel plan, activities need to highlight study link, truly "tour" in "learn", will "learn" into practice.

Teachers in the task of design study travel, should design some tasks to help students explore the development of exploration ability, by doing the task to mobilize the initiative to think, find problems, solve problems, cultivate practical ability, play the subjective initiative, increase the activity of the activity, the student participation, to avoid the phenomenon of "only swim not to learn". From the perspective of travel enterprises, it need to enrich the interest of study travel, enhance the attraction of study travel projects to students, and design good study travel products.

\subsection{Optimization of Study Travel Destinations and Base}

\subsubsection{Gives full play to the function of research and travel resources to create a characteristic culture}

The richness and characteristics of the cultural connotation of research tourism products are the key factors to attract tourists and improve the quality of tourism experience I.[4]. 11.The development of research resources should not be limited to a scenic spot or scenic spot itself, but develop comprehensive research products through resources, integrate its unique regional culture, national culture and historical culture into tourism resources development, deepen the uniqueness and multi-level of research resources, connect tradition and modern, let the students feel nature, history, culture and gain in the study trip I.[7], To meet the needs of study travel.

5.2.2 Set up a cultural participation and interactive experience zone through scientific and technological innovation Study travel is not only an upgrade service of tourism products, but also a branch product of education services. S Study travel pursues more participation, experience and interaction. VR, 3D, artificial intelligence and other technology products are increasingly more widely used in human life, and also bring more inspiration to the product design of study travel. Qian Sun and other companies integrated VR technology into the design of red 
tourism study travel courses in primary and secondary schools in southeast Hubei. They developed a simulated tour system using VR technology, which not only protected the red cultural resources of the research destination, but also achieved the purpose of researchI.[8]. Use science and technology to increase the interactivity, participation and experience of study tours products, which has great significance to the innovation of products.

\subsection{Improves the quality of research}

5.3.1 Improve the evaluation mechanism after the tour

It can start from different evaluation subjects and evaluation methods, and the evaluation of different subjects is conducive to avoid the one-sided nature of a single subject evaluation.

Student evaluation includes students' personal self-evaluation and peer mutual evaluation, and the purpose is to help students reflect and promote self-cognition. You can fill in questionnaires, reports, research results display and other ways, and pay attention to students' learning results and learning process in the setting of problems.

The tutor evaluates the development status of students from the aspect of educational goals, and on this basis, it reflects on and improves the teaching design and the implementation of curriculum resource activities, so as to promote the development of students and the development of curriculum teaching. Observation method, interview, performance evaluation, evaluation of file bag evaluation can be adopted, and the evaluation structure should be compatible with the teaching objectives.

Parent evaluation should become an important resource in the evaluation system of research activities. In the influencing factors of students' learning results, family factors are a part that cannot be ignored. Schools need parents to participate in teaching evaluation activities, put forward constructive suggestions, help schools and teachers better improve the research courses, and jointly promote the improvement of the quality of with teachers and students ' evaluation.

\subsubsection{Strengthen the construction of teachers}

It is very important to strengthen the construction of research and study tutors. It is suggested to start from three aspects: the threshold of entry, welfare treatment and teacher training. First of all, strict assessment and selection of tutors, improve the qualification evaluation mechanism of research tutors, establish clear evaluation and selection standards and procedures, and ensure the training of high-quality research teachers. Secondly, it is necessary to establish a scientific, reasonable and operable evaluation standard, and regularly assess the work responsibilities, code of conduct and guidance level of the study tutors. Finally, it is necessary to improve the treatment of research tutors, attract a number of school teachers with high comprehensive ability and social talents, and expand the team of research tutors I.[9].

\subsection{Strongly supports research trips in rural areas}

\subsubsection{Government increases support for rural areas}

To solve the problem of funding for research activities in rural areas, the government needs to establish special funds for study travel, for poverty-stricken areas, special funds can be allocated to schools according to specific circumstances, and a special supervision mechanism is established to ensure the smooth operation of the funds. Schools should make proper use of funds to carry out research trips, so that study travel in rural areas can be implemented and developed in rural areas.

5.4.2 The government increases support for the construction of research bases in areas with backward resources Develop in areas with relatively backward study travel resources, constantly optimize the construction of research base on the existing basis; for undeveloped study travel places, constantly explore local characteristic tourism resources, expand social resources, develop rural tourism to drive the economic development of rural areas, and lay 
a good foundation for the development of study travel. At the same time, the government should do a good job in the publicity and promotion of local study travel, establish a "one-to-one" assistance mechanism, cooperate with experienced universities, set up study travel development teams in rural areas, adjust measures according to local conditions, establish a relatively stable research practice base, and make up for the shortage of rural study travel. Carry out study trips through public welfare activities and social donations, and pay attention to the development of public welfare undertakings in schools in poor areasI.[9].

5.4.3 Expand the faculty staff and improve their ability to organize research and studies

In order to solve the shortage of rural teachers, the government should encourage college graduates to work in remote areas, improve the welfare treatment of rural teachers, expand the ranks of rural teachers, and ensure that rural areas have enough teachers to implement study trips ${ }^{\mathrm{I} .[10]}$. Secondly, the school can provide professional training for teachers in rural areas to learn relevant theoretical knowledge and invite teachers to teach practical experience to implement the research activities in rural areas.

\subsection{Give full play to the functions of the government}

The government should encourage the transformation and upgrading of study travel products. According to the principle of innovation, diversification and connotation, research enterprises actively develop and design competitive research tourism products. We will explore the qualification identification of research institutions and research bases, explore the research tourism guidance system, formulate industry management standards, and promote the linkage between departments. We will strengthen market supervision and management, standardize price competition, improve the core product system of study travel, optimize the construction of destinations and demonstration bases, and improve the operation quality of study activities. Promote the continuous improvement of management through pilot exploration, experience summary, and classified promotion.

\subsection{Xingshan county study travel development practice provides sustainable development templates}

The development of study travel destination in Xingshan County mainly focuses on the integration of art education courses and local tourism resources. Xingshan County is located in an economically underdeveloped mountainous area, but it has rich historical and cultural resources and natural resources.

The design team's first attempt to develop Chinese ink painting, hopes to use local natural resources with ink painting. In the course design, for children of different age groups, different teaching goals are set and designed in the depth and difficulty of the course. Lower grade children, in grades 1-2, mainly recognize nature; children in grades 3 to 6, understand Chinese ink painting and appreciate the beauty of Chinese traditional art; and junior high school students need to learn traditional painting techniques on the aesthetic basis.

In the course implementation, set grade 3-6 students as the target group, first lead the children to appreciate Chinese ink painting, according to the local resources characteristics choose suitable painting objects, understand the characteristics of the painting object, painting objects can be plants, animals or a scenery, etc., then guide the children with ink painting materials, the finished product will be put into the special custom collection. In the implementation of specific activities, we will simulate the activity process in advance, avoid possible safety risks, and also make the corresponding emergency plans. The number of classrooms is controlled within 20 people, which has a certain guarantee on the teaching effect, classroom order and student safety. The teachers participating in the study trip are teachers or students from art colleges, who have certain artistic ability and literacy. Through the theoretical knowledge research foundation, curriculum research and development, and many classroom experiments.

The development of study travel in Xingshan County has given some solutions to the problems existing in the development of study travel above. In terms of research products, we launched art education courses integrated

ISSN: 0010-8189

(C) CONVERTER 2021 
into the research classroom, enriching the diversity of research products. For example, in ink painting, in the course design, we clarify the teaching purpose of each class — to understand traditional culture and appreciate the beauty of Chinese traditional culture. Each class needs to complete a work, put in the exquisite work collection. Students know that their works should be put into the collection, generally take their own creation seriously, not perfunctory, to avoid the "careless" learning. At the same time, the collection is also conducive to the later course evaluation. Limit the number of classrooms, to ensure the quality of classroom teaching and the quality of students' study travel.

The development of study tourism in Xingshan County can promote the development of tourism resources in Xingshan County, create jobs, stimulate local economic growth through tourism economy, increase residents' income, and promote the development of local education and study travel, and form a virtuous circle, thus forming sustainable development.

Of course, the development of Xingshan County study travel is not necessarily perfect, but there are also deficiencies to improve in the development process. However, such design ideas also provide a feasible reference for the sustainable development of study travel.

\section{Conclusion}

In essence, study travel is the unity of learning and travel I.[11].It is a new curriculum form to cultivate students' social responsibility, innovative spirit and practical ability, and it is an effective means to achieve the overall comprehensive and practical education goal. Study travel has inherited and developed China's excellent traditional study tour, the educational thought of "reading 10,000 volumes, traveling thousands of miles" and the cultural spirit of the Chinese nation, giving new connotation to quality-oriented education. The development prospect of study travel is relatively optimistic. It is hoped that the analysis and strategies provided in this paper can add new impetus to the sustainable and healthy development of study travel.

\section{Acknowledgements}

This work was supported byFoundation Projectof 2019 National Social Science Foundation Art Science Project, Research on the Cultivation Mechanism of Public Art on Youth Values, (Project No. 2019a01315).

\section{References}

[1] Y. Wang, D.P. Chu, F.Y.Lin, et al., "Research hot spots and context evolution of study tours,"Educational Review, pp.132-138, 2021.

[2] "Notice of the General Office of the Ministry of Education on announement of National Research and Practice Education Base and Camp for Primary and Secondary School Students in 2018,'In: No. 84 of the Department of Education,2018.

[3] C.Y. Liu, L.L. Wang, "Problems and solution strategies in the implementation of study tours," Scientific Consulting (ScienceManagement), pp. 81-82, 2021.

[4] C.S. Xie, J.Y. Zhang, "Internal Operation Mechanism and Optimization of Research Tourism," Tourism Studies, vol. 13, pp. 1-13, 2021.

[5] X.F. Zhao, “Teachers should be pioneers in study tours,"China Teacher Daily, pp. 5044-5047, 2017.

[6] "2017 China Family Quality Education Consumption Report released," In: China Education Online. 2017.

[7] China Tourism Research Institute, "China Research and Travel Development Report," Tourism Education Publishing House,pp. 84-85, 2017.

[8] Q. Sun, G.Z.Zhou, “Application of VR Technology in study tours — t takes Red Tourism study tours for Primary and Middle School students in Southeast Hubei as an example," Journal of Hubei Institute of 
Technology (Humanities and Social Sciences), vol. 35, pp. 83-86, 2018.

[9] M.J.Zhou, X.P.Zhang, "Target deviation and path transcendence of study tours in the implementation," Modern primary and secondary education, vol. 35, pp. 92-95,2019.

[10] Z. Ban, C. Zhu, C. Liu, "The Dilemma and Countermeasures of the Study Travel in Rural Schools," Teaching and Management, pp. 15-17, 2017.

[11] J.C.Wang, "Great World Micro Course: The Educational Significance of study tours," Beijing Publishing House, 2018. 